\title{
Comprehensive Strategy Analysis for a Leading Firm in the UAE Precision Tooling Industry
}

Chaher Alzaman* and Molham Chikhalsouk

Business and Engineering Management Department, Higher Colleges of Technology, UAE

\begin{abstract}
This paper conducts an extensive analysis of the strategy of a leading UAE company in the precision tooling industry. The work starts by an introduction about the company and a comprehensive literature review about the strategy concept, how the scholars perceive strategy, and the tools that can be used to assess and analyze strategy. The paper analyzes the company's strategy in the light of Mintzberg's Ten Goals, Mckinzey's 7S model, Porter's Value Chain, Porter's Five Forces, SWOT analysis, and recommendation on Balanced Scorecard for supply chain analysis. Since the company is a leading one and has outreaching involvement in vital UAE businesses such as aerospace and oil and gas, the analysis serves as an insight into strategy for UAE companies.
\end{abstract}

\section{Introduction}

The paper aims at evaluating the depth and criticality UAE companies undertake in strategy building. Since the modeled company is a leading company in its perspective industry and has an encompassing reach over the oil and gas and the aerospace businesses, it can signify a fair understanding about strategy formulation in the UAE.

This paper sheds the light on strategic planning for a UAE leading company in precision tooling. The company core business is to deliver highly precise machining and manufacturing services in the following major business fields of Defense Equipment, Aerospace Equipment, and Oil \& Gas Equipment. The company business is of high risk and competitiveness, which requires high potential and qualitative standards of achievement to Position the company in the right market Position. The vision of the company is to forge a world class precision manufacturing infrastructure serving as an industrial backbone to the UAE industries. The paper performs analysis for the UAE Company utilizing Mintzberg's strategy evolution process, McKinsey 7-S framework, and Porter's value chain. Further analysis is performed using Porter's Five Forces, SWOT analysis, and Balanced Scorecard (BSC).

The business environment surrounding the company is quite competitive. Many suppliers are available in the market since the Gulf States are putting a lot of emphasis on defense. The suppliers originate from broad spectrum. The suppliers originate from many different countries such as the US, Russia, England, France, China, and other emerging nations. The market size is quite considerable since the Gulf States are putting top priority on defense. In regard to research and development, the company has several joint ventures with leading companies in the world. This makes their products very advanced.

\section{Literature Review}

In order to analyze an organization and its level of productivity, efficiency and success, it is important to define its operation strategy and analyze it. Advantageously, there are some approaches that help in understanding and analyzing its strategy such as Porter's five forces, McKenzie 7S framework and the Mintzberg's strategy evaluation process. Moreover, the Balanced Scoreboard is another tool that is used to evaluate the performance of the organization and how are their achievements close to their vision. To begin, researchers have made aggressive efforts in defining, studying, and evaluating strategy. Different perspectives and analysis of Operation Strategy (OS) are presented in the literature review.
Mintzberg [1] defined strategy as 'the Pattern in stream of significant decisions'. Porter highlighted a major question: What Is Strategy? In his paper he differentiated between the strategy and operational effectiveness. 'Operational effectiveness and strategy are both essential to superior performance, which, after all, is the primary goal of any enterprise. But they work in very different ways' [2]. Strategy is not that simple and hence, different scholars tried to study it more thoroughly. For example, Mintzberg [3] introduced a new approach in the comprehension of strategy. The approach is the 5 P's which are Plan, Ploy, Pattern, Position, and Perspective. These concepts broaden the angle that determines the role of the strategy in an organization. The Plan refers to the predetermined direction that the organization intends to lead to, while the Ploy assures that the strategy is going towards the realm of direct completion. Pattern focuses on actions. Mintzberg points out that 'the concept is an empty one if it does not take behavior into account'. If we want to see our organization's Position with respect to its competitors, the Position dimension helps us to look at organizations in context. Finally, perspective 'raises intriguing question about intention and behavior in a collective context' [4].

Drobis [5] believes that any strategy must be set and should be designed to achieve substantial competitive advantages. "In the long run, if you do not achieve a competitive advantage you would not have a profitable business. And in order to understand what the advantage would be, you must understand your customer needs and how you compare to your competitor in the ability to deliver value to your targeted customers; that is the core of effective decision-making in any company," [5].

Mintzberg [1] stressed that the fundamental issues that determine the level of the strategy success is creativity and keen understanding of the organization's objectives. 'Managers take one narrow perspective or

${ }^{*}$ Corresponding author: Dr. Chaher Alzaman, Business and Engineering Management Department Higher Colleges of Technology, UAE, E-mail: calzaman@hct.ac.ae

Received January 28, 2013; Accepted March 04, 2013; Published March 06 , 2013

Citation: Dr. Alzaman C, Chikhalsouk M (2013) Comprehensive Strategy Analysis for a Leading Firm in the UAE Precision Tooling Industry. J Bus \& Fin Aff 2:107. doi:10.4172/2167-0234.1000107

Copyright: ( 2013 Dr. Alzaman C. This is an open-access article distributed under the terms of the Creative Commons Attribution License, which permits unrestricted use, distribution, and reproduction in any medium, provided the original author and source are credited. 
another- the glories of planning or the wonder of learning, the demands of external competitive analyses or the imperatives of an internal "resource-based" view' [1].

Strategy has witnessed several stages of evolution. This is because of the change in the economic activities and learning and exploring the optimal ways to improve our organizations performance and revenues. Mintzberg [4] studied the strategy evolution and classified it into ten schools (streams). The Design School is the oldest school based on a simple concept which is we format our strategy according to the organization internal strengths and weaknesses and fit it perfectly with external opportunities and threats. The Planning School is prevalent in machine- type organization. In this school, the planning staffs play the most important role in the strategy formation and replace senior managers. The Positioning School is a kind of "Strategy Reduction", where reduced to general Positions chosen for formalized analyses of industry situations [4]; and the planners are replaced with analysts. The need for the analysts is fundamental, where they can sink too deeply in data and prompt their scientific truths to their clients. The Entrepreneurial School shifts the process for precise designs, plans to vague visions (wide perspectives). The process is centered about the Chief Executive (CE). It can be seen in dynamic organizations. The Cognitive School is the school of creative strategy. It is does not rely on the reality mapping but it goes beyond that and proposes a creative strategy that leads the organization to higher levels of success. The Learning School is the practical school (Emergent Process). This school assumes that the strategy is emergent; and we can develop our strategy from our own organizations. The intertwining between the formulation and implementation is used in this school. The Power School is the power of negotiation school as an orientation in strategy making. There are two orientations can be recognized by this school, which are Micro Power and Confrontation Power. The Micro Power suggests that the strategy progress inside the organization is a result of political- a process involving- argument. And the Confrontation Power is among parties who divide the power. It is focused on self-interest and fragmentation. The Cultural School has started in Japan and became popular in the USA in the 1980s. This school is reverse of the Power School. It is focused on common interest and integration. Hence, the strategy formation is seen as a social process bounded with cultures and we cannot sometimes modify our strategy because of the culture influence. Environmental School is connected to the "Contingency theory" which predicts what response under environmental conditions and population ecology can limit our strategy choices. It is a hybrid between the cognitive and power schools. It is also influenced by the "Institutional Pressures" which is concerned with the institutional pressure faced by organizations. Configuration School happens when an organization is moving from a level to another; this will be as transformation (configuration) process. In practice, more than one school can be seen for one organization strategy.

In 1988, Mintzberg proposed criteria for strategy evaluation due to the different and broad meaning for strategy. He guaranteed that any strategy should fit within one or more of the criteria he proposed. The criteria are contingency that must not present mutually inconsistent goals and policies, consonance in which the strategy must represent an adaptive response to the external environment, advantages that must provide for creation and/or maintenance of competitive advantages, and feasibility that will neither overtax available resources nor create unsolvable sub problems. Hence any strategy that will not meet one or more of the previous criteria is a suspect [6].

Alternatively in 1996, Porter [2], a Harvard business professor, proposed a model that is now commonly used to analyze industries and competitive structures. Porter's Five Forces model is a powerful tool that combines five competitive forces which limit any industry's profit according to external factors. These forces are the threat of new entrants, the customer bargaining power, the supplier bargaining power, the substitution to an alternative product or service, and the intensity of competition among current rivals inside the industry.

Alternatively, Boyer et al. [7] comment that operation strategy refers to the decisions and plans involving developing, Positioning, and aligning managerial policies and needed resources for consistency with the overall business strategy [7]. While Cousins [8] highlights that there are some situations when the outcomes do not come as they have been planned. This is because of the 'mismatch between the way resources are dePloyed and the competitive priorities established by the firm' [8].

Furthermore, Peters and Waterman [9] published a book about the most successful companies in 1980's. They proposed the McKinsey 7-S model. The book came as an extensive study for 'leading 1980s companies with records of long-term profitability and continuing innovation' [9]. According to the 7-S model, there are seven factors that shape a strategy and make it effective; these factors are: strategy, structure, systems, staff, skills, style (Culture), and shared value. The McKinsey 7-S model factors can be divided into hard elements and soft element. Hard element, which includes strategy, structure, and system, can be easily discovered and controlled by the management:

- Strategy: The Plan implemented to keep the company ahead of its competitors.

- Structure: The Position of each emPloyee in the company, and to whom he reports.

- System: The operations and activities done by each emPloyee to complete the job.

Soft elements are more complicated to identify and are usually influenced by the culture of the company and its environment.

- Shared values: These are the values that the company was founded on.

- Style: Adopting a leadership style.

- Staff: The emPloyees and their qualifications and the ability to accomplish their jobs.

- Skills: The proficiency and expertise of the emPloyees.

KaPlan [10] mentions that the diagram for the 7-S model looks like a spider web, where each of the 'S's' connecting to the other six. Carlos and Morris [11] citing other studies classify strategy, according to the stage of implementation, into three models of static, dynamic, and mixed models. The 7-S lies in the static model and every S emphasizes specific dimensions of the organization [11]. The strategy should be flexible and modifiable to absorb any external changes and maintain the organization at a maximum profit level. KaPlan and Norton [12] stated that 'It's more effective to choose a design that works reasonably well, and then develop a strategic system to tune the structure to the strategy'.

\section{Analysis}

\section{Mintzberg's ten goals}

To begin, based on the company mission, vision, and Functional Organizational Chart (FOC), the following observations have noted that he organization has social role in the development of the country by preparing national manpower that helps in enabling a sustainable 
industry. With accordance to Mintzberg's ten strategy schools, we found that the organization implements a strategy that is a blend of different schools. The strategy is a blend of design, planning, entrepreneurial, and cultural schools. While, it appears that there is no significant influence for the other schools. From the Design School perspective, the company starts from its internal strengths and weaknesses and aims to take advantages of its strengths to gain new customers, enter new markets, and manufacture new products. From the Planning School, the company is a high tech company and its state of the art machines are the core of this industry. Here, its strategy is machine-centric; the organization seems to place technology and state of the art machine procurement at the center of its strategy. The decisions and the strategy are developed from the B.O.D. and C.E.O. levels and hence there is a hint of Entrepreneurial School. The company also resembles the strategy of Cultural School as the company adopts social goals and aims to contribute to the community and develops the national manpower to enable sustainability. Concerning the other schools, the company shows no significant influence in them as illustrated in the following:

- Positioning School: The Company has a strategy and there is no strategy reduction, and the important decisions are taken from the highest level.

- Cognitive School: The organization is new (started in 2007), and they are still in learning and establishing stages and they have not reached to the cognitive level and creative strategy.

- Learning School: In order to avoid any additional losses, the organization is stick to its strategy and they do not modify the strategy. Also, the three years can be considered as a building stage for experience and data collecting that enables the organization to learn from.

- Power School: The Company is a young company and they are trying to build their name and reputation. The company does not have the bargaining power over the customers. This is because of the high completion in this industry and reputation of the other competitors.

- Environmental School: This industry does not expose a real impact on the environment. Hence, the company can expand without any serious impact on the environment.

- Configuration School: As mentioned before, the company with its recent start did not reach to this transformation stage.

\section{The McKinsey7S model}

The McKinsey 7-S framework is a technique to evaluate a company's performance in order to identify its Position in a certain industry. This technique helps in improving the performance of a company by looking at the effect of changes on it, aligning the departments, and deciding the best way for implementing a strategy.

Strategy

The company is continuously searching for the latest technologies and implementing them to improve the operations performance and customer satisfaction. The company aims at providing high quality products to regional and international customers. Accordingly, the company has adopted rigorous standards and rules to maintain high internationally recognized quality qualifications. Hence quality is important in the company's strategy as after being established to provide products for the defense industry, the company grew in a short period to serve the aerospace and oil \& gas industries due to its outstanding quality records. The company is continuously acquiring quality certifications from well reputed bodies and establishing good relations with suppliers to ensure good quality and the sustainability of their resources. The company is also gearing its strategy towards the environment as it is more and more involved in projects that have an impact on the UAE and regional environment.

\section{Shared values}

Through our review of the company's mission and the overall work environment, the company's shared values have cohesiveness around the importance of a friendly and safe work environment: a foundation stone for the company. The company applies the regulations of health, safety, and environmental set by international recognized certification bodies.

\section{Structure}

As shown in Figure 1, the structure of the company resembles a common hierarchal tree found in most companies with functional departments. EmPloyees report to their direct supervisors and tasks coming from other departments or higher management Position has to go through the supervisor before being carried out by the emPloyee. This could be an impediment to collegiality.

As in many of the manufacturing organizations, the operations department plays a pinnacle part. The sub-departments under operations are concerned with planning the production of new items and improving the production of existing items, purchasing raw material to produce the item, production, logistics and inventory, and quality and control. The operational processes are set by the operations manager and approved by the strategy development manager and the C.E.O. based on financial analysis, cultural constraints, and standards and rules required by the government and the certification bodies.

Style

The company assigns each year a significant budget for training purposes. All emPloyees including all level management are required to attend at least one seminar or workshop relating to their duties in a year. The board of directors usually doesn't address operations issues. It is the C.E.O. and the Strategy Development Manager who deal with operations issues.

Staff

The company has a priority to recruit UAE Nationals whenever possible. It is making immense efforts in preparing UAE Nationals for the precision industries by partnering with educational institution.

Skills

The company aims to hire well qualified workers with international experience to ensure worldwide competency. The company holds multiple skill management seminars for managers aiming to assist them in achieving the goals and strategy of the company.

\section{Porter's Value Chain}

Operations strategy for a manufacturing company is more than transforming raw material into valuable goods. Companies should be able to create the greatest possible value for their customers. A useful 
tool for analyzing value in a company would be Porter's Value Chain [13].The work chooses the following three steps to perform value chain Analysis:

\section{- Activity analysis}

The evaluated the activities carried from production till delivery at two levels. The company should map all the activities at the organization and personal level

- Organizational level: Going in depth into all the business processes: marketing, sales, operations, delivery, support, etc.

- Personal level: Recruiting skilled emPloyees, motivation, keeping updated with the latest techniques, seeking feedback from customers.

\section{- Value analysis}

Trying to figure out how more value can be added in the eyes of the end customers (Table 1). Most important is to identify the value factor of each activity and what should be done in order to obtain a better value. Table 1 identifies value factors of great importance to the company.

\section{- Evaluation and planning}

Decisions should be taken whether the changes should be implemented by the company. A smart move would be to start by easy, quick, and cheap tasks, guaranteed to succeed. Prioritization of the tasks is important in this step.

\section{Porter's five forces}

Many organizations use Porter's five forces analysis to evaluate their potential in making profits within a given industry. Figure 2 explains well Porter's Five Forces.

The first force to analyze is the Bargaining Power of Buyers. Buyers in all the different market, which the company functions in, have a good bargaining power due to the criticality of quality in precision tooling. This is more pronounced in the aerospace industry where customers perceive products more in terms of value: the buyer is looking for high quality, low cost goods. They are looking for quality and cost. In this market international suppliers are a real threat. Hence, the company keeps the buyer interest in mind.

Second is the Bargaining Power of Suppliers. Due to the nature of precision tooling, parts can be procured from a variety of vendors. There a large pool of vendors and hence the company can assert its imperatives in controlling cost and improving quality.

Third is the Relative Power of Stakeholders. Shareholders of the company have a visionary and strategic view of the company. The company is UAE based which entrusts the shareholders and also impacts on the social benefits. Furthermore, the company has been successful in entering new market, which in all has satisfied the shareholders. The company should invest more in hiring UAE nationals and winning important contracts in the UAE to sustain the support of the shareholders.

Next is the force of New Entrants. We choose important factors that influence the threat of new entrants which are economies of scale, product differentiation, capital requirement, switching cost, and access to distribution channels. In terms of economies of scale, the company is making good strands towards economy of scale but it is still lacking and hence affection the company's performance. This is an opportunity

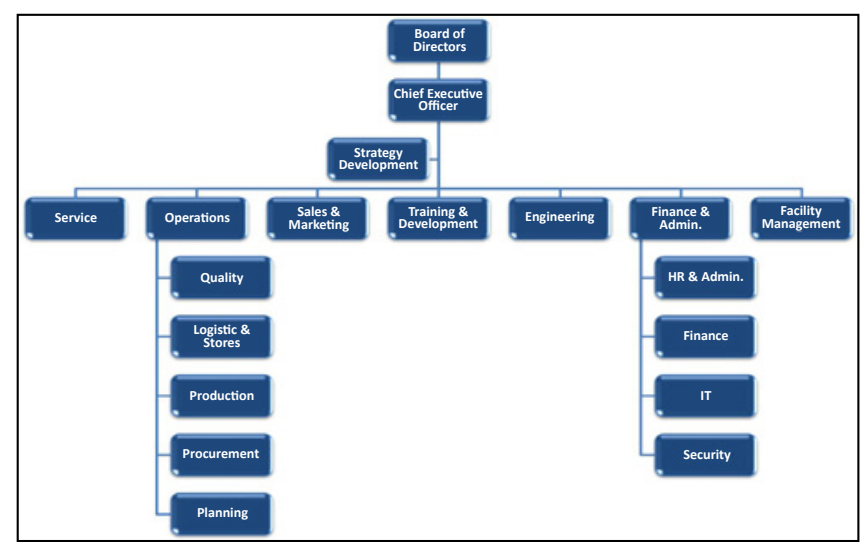

Figure 1: Company's Organizational Structure (EPI HR Department 2009) System.

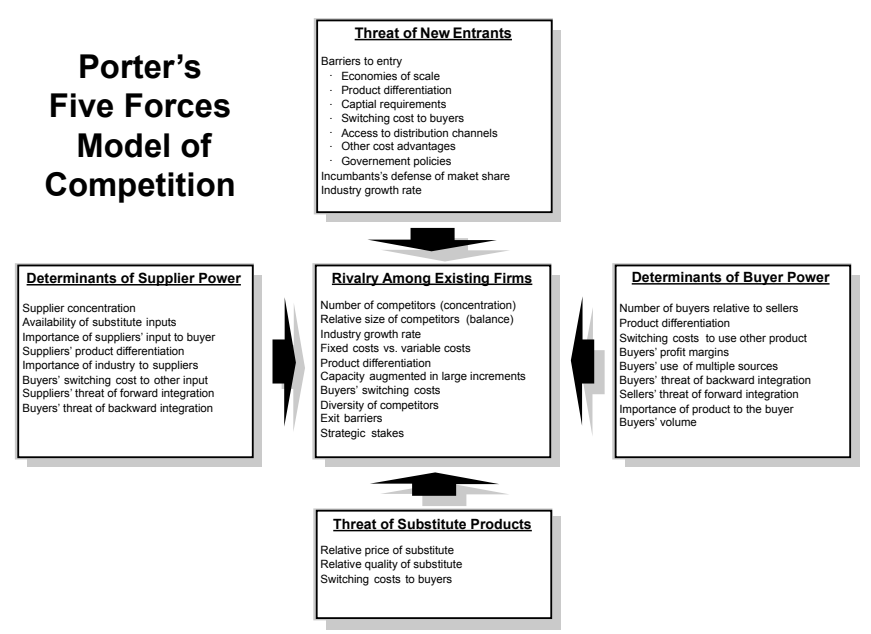

Figure 2: porter's five forces structure (strategic advantage 2005).

which the company can focus on. In terms of product differentiation, the company has a strong competitive advantage in product differentiation. It answers to customers' specification very well. In terms of capital requirements, as many of the precision industry, the capital requirement is quite intensive especially in the start-up phase. The technology needed in this industry is quite expensive. It is a major factor that could be a threat for the company. The company has been aggressively investing in technology but unless it can translate that into higher production and higher value, this would impede the company's bottom line of profit. In terms of Switching Cost, this is an area of strength for the company as it has not faced problem in switching from market to another. This is due to the nature of the industry, as precision tooling is quite extendable and could entertain the criteria of different industries. It has been not difficult for the company to switch from one market to another as the machines are not customized for certain products. The machine can be used for different product which gives an opportunity for the company but certainly affect the company's ability to mass produce. The company needs to find the right balance between customization and mass production. Finally concerning Access to Distribution channels, for new entrants, access to distribution channels could be a hinder while given the company's ongoing projects and extensive experience with the UAE. It has built for itself a good base for access into distribution 


\begin{tabular}{|c|c|c|}
\hline Value Chain & Value Factors & Changes Needed \\
\hline $\begin{array}{c}\text { Purchasing Raw } \\
\text { Material }\end{array}$ & $\begin{array}{l}\text { Building the best rela- } \\
\text { tions with suppliers } \\
\text { Getting the maximum } \\
\text { value for purchased } \\
\text { products } \\
\text { - Getting the best qual- } \\
\text { ity of raw material }\end{array}$ & $\begin{array}{l}\text { - Making deals with the } \\
\text { maximum number of } \\
\text { suppliers to create } \\
\text { competition between } \\
\text { them } \\
\text { - Purchasing higher } \\
\text { number of products to } \\
\text { control the price } \\
\text { - Forcing standards } \\
\text { of the suppliers to } \\
\text { get the best quality } \\
\text { products }\end{array}$ \\
\hline & $\begin{array}{l}\text { - Minimizing manufac- } \\
\text { turing throughput time } \\
\text { - Reducing operational } \\
\text { costs } \\
\text { - Increase utilization of } \\
\text { the company's opera- } \\
\text { tional capacity }\end{array}$ & $\begin{array}{l}\text { - Creating an operation } \\
\text { strategy to minimize } \\
\text { the time and cost for } \\
\text { manufacturing } \\
\text { - Using all available } \\
\text { resources in the man- } \\
\text { ufacturing process in } \\
\text { an effective way }\end{array}$ \\
\hline Sales \& Marketing & $\begin{array}{l}\text { Having a complete } \\
\text { database containing } \\
\text { all the potential clients } \\
\text { - Making the product } \\
\text { popular } \\
\text { - Selling all the manu- } \\
\text { factured products }\end{array}$ & $\begin{array}{l}\text { Making a long term } \\
\text { marketing plan } \\
\text { Searching for high } \\
\text { potential clients } \\
\text { Proposing the best } \\
\text { pricing scenarios to } \\
\text { maximize sales. }\end{array}$ \\
\hline Delivery & $\begin{array}{l}\text { Delivery all the } \\
\text { required products with } \\
\text { the exact specifica- } \\
\text { tions } \\
\text { - Always delivering on } \\
\text { time }\end{array}$ & $\begin{array}{l}\text { - Taking care of every } \\
\text { purchase order to } \\
\text { make sure that the } \\
\text { packed products } \\
\text { match the require- } \\
\text { ments } \\
\text { - Finding more efficient } \\
\text { and reliable ways for } \\
\text { delivery } \\
\text { - Should consider JIT }\end{array}$ \\
\hline Support & $\begin{array}{l}\text { - Replacing defected } \\
\text { products }\end{array}$ & $\begin{array}{l}\text { When costing the } \\
\text { product, the selling } \\
\text { price should reflect } \\
\text { the cost of replacing } \\
\text { a certain number of } \\
\text { defective products } \\
\text { - Statistical Process } \\
\text { Control can be used } \\
\text { to minimize defectives }\end{array}$ \\
\hline
\end{tabular}

Table 1: Porter's Value Chain Analysis

channels. However, the company might need to invest more to compete regionally.

Next in our discussion is Rivalry among Existing Firms. Here we analyze the number of competitors, the product or service characteristics, the overhead costs, capacity, and exit high barrier cost. In terms of the Number of Competitors, given the quality level at which the company functions, competition is quite scarce. Also, given the high capital requirement in the precision tooling industry, it is quite difficult for companies to compete on high quality products and services; with the exception of the aerospace industry where competitors are global. In terms of Product or Service Characteristics, the main factor for success for our model company is its excellent quality standings. The company retains important customers in this manner. Correspondingly, this makes it very difficult of new entrants to attract the company's important customers. This is a key to the company's competitive advantage. In terms of overhead costs, fixed costs maybe the main threat on the existence of the company as it is in its start-up phase as there are a high amount of fixed costs associated with the operations runs regardless the amount or production. CAPIX is a critical issue as all machines are depreciated. In terms of capacity, the capacity non-flexibility is

affecting the company's productivity. The ability of the company to increase its capacity to accept more orders from customers is limited. This is an area which the company should concentrate on. Finally for exit barriers, as mentioned before the company has a strong record in switching between industries. The company can exit markets effectively and soundly as it has done in the past.

Overall, we can conclude that the modeled company has a great opportunity to succeed in its respective market given it invests more in the opportunities discussed and improve in the areas where improvement is needed such as capacity, overhead costs, and economies of scale. In the aerospace market, the company should invest heavily in those elements to reduce cost

\section{SWOT Analysis}

A SWOT analysis, Table 2, was carried. From the SWOT analyses, it is clear that the organization faces serious difficulties on the supply chain level. Hence, using Balanced Scorecard (BSC) in the supply chain process, the supply chain can be analyzed further: This is done in the next section. In general, strategies are executed through short-term goals, functional tactics, and staff motivations.

- Well established direct contact with
- -
- Secual aerospace OEMs.
gionally through Offset program due
to customer base in defense and civil
aerospace.
aerospace.

- Raw material available for oil \& gas components.

The company is one of the shops for the manufacturing of oil \& gas migh manufacturing capabilities.

- Close proximity with customers in the oil \& gas industry.

- Outsourcing of repair and maintenance services of oil industry.

High level of experience and knowledge of local defense market.

Outsourcing of repair services.

\section{Opportunities}

Aviation and airline fleets market growth domestically and regionally. - Government efforts to diversify the UAE economic by moving to aerospace industry.

- Advantage of cost position in Middle East aerospace industry.

Government support in getting the supply contracts of approved components to oil \& gas industry.

- High demand for low cost components in the oil \& gas industry (e.g. Flanges, bolts, gaskets...etc)

Low competition on local level for the - Growing competition locally.

high technology oil industry compo- - Lack of modules and system assemnents (like drill heads, valve

Growing PMA (Parts Manufacturer capacity and securing contacts with defense.

- Economic crisis lead to cancellation

\section{Threats}

The difficulties to get the complete aviation authority certification. of orders for many OEM (Original Equipment Manufacturer).

High competition located in low-cost region.

- Difficulties in preserving the needed skilled talents.

- Difficulties in acquiring the complete aviation authority certification.

- High international competition from China \& Korea. blers of oil's equipment.

- Required Industry's certification skilled workforces.

- Cross-Country entry barriers affecting competition.

- Cost Optimization due to Economic Crisis.

- High requirements to attract the required talented workforce beside the difficulties to preserve talented workforce.

Table 2: SWOT Analysis. 


\section{Short Term vs. Long Term}

The company with the assistance of external partners on the short term is trying to gain some local market and enter new foreign market mainly in the Middle East and Africa. The main objective in the short run for the company is to win the confidence of defense contractors and render good reputation. Immediately, the company should capitalize on the market growth. At the start, the company had considerable investment and was able to allocate it effectively. And from the very start, the company had significant amount of funds that enabled it to hire talented personnel who have clear understanding of the products and markets of which to penetrate. In the long term, the company should dominate the local and surrounding markets. Given that the company is UAE-based, this should give it a strong future presence in the UAE and also accessibility to Middle East markets.

\section{Conclusion}

Initially, it is important to state that the modeled company has far reaching arms into different businesses in the UAE and faces competition locally, regionally, and internationally as many other companies in the region. The modeled company is much aware of the importance of strategy. As many other companies in the gulf region, strategy is critical for the company to have a sound business strategy. From this work, the company seems to focus on its strengths, weaknesses, opportunities, and threats in the formulation of its strategy. The company also puts a lot of stress on planning as it continuously seeks new technologies that would render competitive advantage. The company also places emphasis on recruiting UAE nationals to gain support of society- an important stakeholder for any company. Alternatively, the company does not put emphasis on Positioning. The company doesn't prioritize studying the market and analyzing what other world class companies are doing.

A very important component of the company's strategic thinking is quality. In the precision industry quality is all important. Here small minor errors are not allowed. For this, the company is committed to fishing out the latest technologies. The shared values of the company also show dedication to providing good work environment. While the company's hierarchal structural is quite traditional. This quite important in the region where hierarchal structure requires progression.

Some of the potential problems inherited in the company might be due to the classical hierarchal structure which lacks the flexibility required to respond to market changes or cost avoidance opportunities. The company needs to have a more flexible structure in order to be more responsive. The company should alternatively focus on niche products and excellence in quality keeping in mind that the necessity of the market is excellent quality.

\begin{tabular}{|c|c|c|}
\hline Performance Measure & Primary measures & Secondary measures \\
\hline $\begin{array}{l}\text { Customer satisfaction/ } \\
\text { quality }\end{array}$ & $\begin{array}{l}\text { Perfect order fulfillment } \\
\text { Customer satisfaction } \\
\text { Product quality }\end{array}$ & \multirow{4}{*}{$\begin{array}{l}\text { Delivery- to- commit date } \\
\text { Warranty costs, returns, } \\
\text { allowances } \\
\text { Supply chain response } \\
\text { time } \\
\text { Product plan achievement } \\
\text { Value-added productivity } \\
\text { Forecast accuracy } \\
\text { Inventory obsolescence } \\
\text { Capacity utilization }\end{array}$} \\
\hline Time & Order fulfillment lead time & \\
\hline Cost & Total supply chain costs & \\
\hline Assets & $\begin{array}{l}\text { Cash-to cash cycle time } \\
\text { Inventory days of supply } \\
\text { Asset performance }\end{array}$ & \\
\hline
\end{tabular}

Table 3: Measures to improve supply chain measurements in PI (Handfield and Ernest, 1999).
Advantageously, the company evaluates its value factors very well and is quite aware of what is important to the customer. Quality is over and over again identified as important. In line to Porter's Five Forces, identified rivalry among existing firms as important. The company incurs a high fixed cost due to high product differentiation. This is tradeoff between customer customization and mass production. Also, capacity is another problem the company is facing and limited capacity could threaten customers' loyalty.

Since the company focuses on its strengths, weaknesses, opportunities, and threats in the formulation of its strategy, then a SWOT analysis becomes important. The paper performed a SWOT analysis and the findings shine the light on the challenges arising from the aerospace business where competition is ripe. One of the weaknesses identified is in the supply chain. The company requires JIT supply chain capabilities. It is advisable that the company reassesses its supply chain partners and further analyzes its supply chain capacity requirements. As form of recommendation the company should perform Balanced Scorecard (BSC). In the BSC, there are four strategy processes that are addressed [12], which are:

\section{- Financial perspective}

- Customer perspective

- Process (internal) perspective

- Innovation and learning (training) perspective

This work recommends applying BSC to supply chain performance measurements. In BSC, we the supply chain goals and strategy are aligned with the entire performance measures. We need to apply the BSC on the different (four) levels of the supply chain and these levels are:

- Supply chain

- Organization

- Function

\section{- Team/individual}

The improvements on the supply chain level will definitely lead into improvements on the organization level. The chain supply goals, strategies, and performance measures at its level will be led to the organization level, which will improve the function level. As a last step, the team level will improve depending upon the functional level. For every level of the four forgoing levels, the BSC address the four keys (customer, financial, internal, and innovation), and within each area, the fundamental objectives are characterized and the entire performance measures, performance targets, and new ideas and plans are developed. Handfield and Ernest $[14,15]$ proposed a measure of supply chain performance. We strongly recommend the organization to apply it in order to improve the process by improving the supply chain measurements.

\section{References}

1. Mintzberg H (1972) Research on Strategy Making. Proceedings of the Academy Of Management Conference. First Notions of Strategy as Pattern 29-34.

2. Porter ME (1996) What is strategy? Harvard Business Review 74: 61-79.

3. Mintzberg H (1987) The Strategy Concept I: Five Ps for Strategy. California Management Review 30: 11-25.

4. Mintzberg H, Lampel J (1999) Reflecting On Strategy Process. Sloan Management Review 40: 21-30.

5. Drobis, David R (1991) Competitive Thinking for Competitive Advantage. Public Relations Quarterly 36: 9-13. 
Citation: Dr. Alzaman C, Chikhalsouk M (2013) Comprehensive Strategy Analysis for a Leading Firm in the UAE Precision Tooling Industry. J Bus \& Fin Aff 2:107. doi:10.4172/2167-0234.1000107

Page 7 of 7

6. Rumelt R (1999) Note on Strategy Evaluation. The Anderson School at UCLA 1: 1-12.

7. Boyer K, Swink M, Rosenzweig ED (2005) Operations Strategy Research in the POMS Journal. Production and Operations Management 14: 442-449.

8. Cousins PD (2005) The alignment of appropriate firm and supply strategies for competitive advantage. International Journal of Operations \& Production Management 25: 403-428.

9. Peters T, Waterman R (1982) In Search of Excellence: Lessons from Americas Best Run Companies. Harper \& Row, USA 51-85.

10. Kaplan RS (2005) How The Balanced Scorecard Complements The Mckinsey 7-S Model. Strategy \& Leadership 33: 41-46.

11. Carlos JF, Morris DS (2001) The implications of service quality gaps for strategy implementation. Total Quality Management \& Business Excellence 12: 825833.

12. Kaplan RS, Norton DP (1996) Using the Balanced Scorecard as a Strategic Management System. Harvard Business Review 74: 75-86.

13. Krishnan R, Szmerekovsky J, Cowing M (2009) An Examination of InterFirm Cooperative Arrangements of U.S. Manufacturing Firms. Journal of Transnational Management 14: 16-26.

14. Handfield RB, Ernest NL Jr (2002) Supply Chain Redesign: Transforming Supply Chains into Integrated Value Systems. Prentice Hall, New Jersey $101-$ 180

15. Handfield RB, Ernest NL Jr (1999) Introduction to Supply Chain Management. Prentice Hall, New Jersey 27-84. 